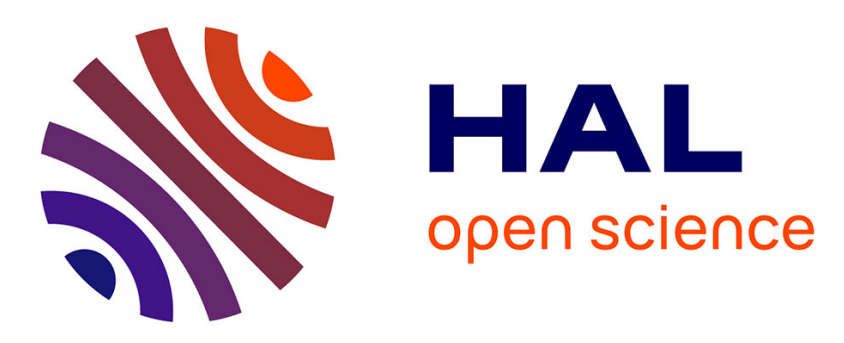

\title{
The Schumann Resonance: a Tool for Exploring the Atmospheric Environment and the Subsurface of the Planets and their Satellites
}

F. Simões, R. Grard, Michel Hamelin, J.J. López-Moreno, K. Schwingenschuh, Christian Béghin, Jean-Jacques Berthelier, J.-P. Lebreton, G.J.

\author{
Molina-Cuberos, T. Tokano
}

\section{To cite this version:}

F. Simões, R. Grard, Michel Hamelin, J.J. López-Moreno, K. Schwingenschuh, et al.. The Schumann Resonance: a Tool for Exploring the Atmospheric Environment and the Subsurface of the Planets and their Satellites. Icarus, 2008, 194 (1), pp.30-41. 10.1016/j.icarus.2007.09.020 . hal-00499084

\section{HAL Id: hal-00499084 https://hal.science/hal-00499084}

Submitted on 9 Jul 2010

HAL is a multi-disciplinary open access archive for the deposit and dissemination of scientific research documents, whether they are published or not. The documents may come from teaching and research institutions in France or abroad, or from public or private research centers.
L'archive ouverte pluridisciplinaire HAL, est destinée au dépôt et à la diffusion de documents scientifiques de niveau recherche, publiés ou non, émanant des établissements d'enseignement et de recherche français ou étrangers, des laboratoires publics ou privés. 


\section{Accepted Manuscript}

The Schumann Resonance: a Tool for Exploring the Atmospheric Environment and the Subsurface of the Planets and their Satellites

F. Simões, R. Grard, M. Hamelin, J.J. López-Moreno, K. Schwingenschuh, C. Béghin, J.-J. Berthelier, J.-P. Lebreton, G.J. Molina-Cuberos, T. Tokano

PII: $\quad$ S0019-1035(07)00477-0

DOI: $\quad$ 10.1016/j.icarus.2007.09.020

Reference: $\quad$ YICAR 8477

To appear in: Icarus

Received date: 2 February 2007

Revised date: 19 September 2007

Accepted date: 20 September 2007

Please cite this article as: F. Simões, R. Grard, M. Hamelin, J.J. López-Moreno, K. Schwingenschuh, C. Béghin, J.-J. Berthelier, J.-P. Lebreton, G.J. Molina-Cuberos, T. Tokano, The Schumann Resonance: a Tool for Exploring the Atmospheric Environment and the Subsurface of the Planets and their Satellites, Icarus (2007), doi: 10.1016/j.icarus.2007.09.020

This is a PDF file of an unedited manuscript that has been accepted for publication. As a service to our customers we are providing this early version of the manuscript. The manuscript will undergo copyediting, typesetting, and review of the resulting proof before it is published in its final form. Please note that during the production process errors may be discovered which could affect the content, and all legal disclaimers that apply to the journal pertain. 
Title: The Schumann Resonance: a Tool for Exploring the Atmospheric Environment and the Subsurface of the Planets and their Satellites.

\section{Authors:}

F. Simões ${ }^{1, *}$, R. Grard ${ }^{2}$, M. Hamelin ${ }^{1}$, J.J. López-Moreno ${ }^{3}$, K. Schwingenschuh ${ }^{4}$, C. Béghin ${ }^{5}$, J.-J. Berthelier ${ }^{1}$, J.-P. Lebreton ${ }^{2}$, G.J. Molina-Cuberos ${ }^{6}$, T. Tokano ${ }^{7}$

\section{Affiliations:}

1) CETP/IPSL-CNRS 4, Avenue de Neptune, 94107 Saint Maur, France.

2) Research and Scientific Support Department, ESA-ESTEC, Keplerlaan 1, 2200 AG Noordwijk, The Netherlands.

3) Instituto de Astrofisica de Andalucia IAA-CSIC, Camino Bajo de Huetor, 50, 18008 Granada, Spain.

4) Space Research Institute, Austrian Academy of Sciences, Schmiedlstrasse 6, 8042 Graz, Austria.

5) LPCE-CNRS, 3A, Avenue de la Recherche Scientifique, 45071 Orléans cedex 2, France.

6) Applied Electromagnetic Group, Department of Physics, University of Murcia. Murcia 30100, Spain.

7) Institut für Geophysik und Meteorologie, Universität zu Köln, Albertus-Magnus-Platz, 50923 Köln, Germany.

\section{Number of Manuscript Pages: 24; 34 (with references)}

\section{Number of Figures: 10}

\section{Number of Tables: 3}


Proposed running head:

The Schumann Resonances of Planets and Satellites

\section{"Corresponding author:}

Fernando Simões

Address: 4, Avenue de Neptune, 94107 Saint Maur, France.

Phone: +33 (0)1 451142 73; Fax: +33 (0)1 48894433.

e-mail: Fernando.Simoes@cetp.ipsl.fr. 


\section{Abstract:}

The propagation of extremely low frequency (ELF) electromagnetic waves and resonance phenomena in the Earth atmosphere has been extensively studied, in relation with ionospheric dynamics, and thunderstorm and lightning activities. A similar investigation can be performed for any other planet and satellite environment, provided this body is wrapped into an ionosphere. There are, however, important differences between Earth and other bodies, regarding the surface conductivity, the atmospheric electron density, the ionospheric cavity geometry, and the sources of electromagnetic energy. In a first approximation, the size of the cavity defines the range of the resonance frequency; the electron density profile, up to the upper atmospheric boundary, controls the wave attenuation; the nature of the electromagnetic sources influences the field distribution in the cavity; and the body surface conductivity, which gives the reflection and transmission coefficients, indicates to what extent the subsurface can be explored. The knowledge of the frequencies and attenuation rates of the principal eigenmodes provides unique information about the electric properties of the cavity. Instruments capable of monitoring the electromagnetic environment in the ELF range are, therefore, valuable payload elements on balloons, descent probes and landers. We develop models for selected inner planets, gaseous giants and their satellites, and review the propagation process of ELF electromagnetic waves in their atmospheric cavities, with a particular emphasis on the application of the Schumann resonance observation to subsurface studies. The instrumentation suitable for monitoring the electromagnetic environment in geophysical cavities is briefly addressed.

\section{Keywords:}

Planets; Interiors; Atmospheres; Ionospheres; Lightning. 


\section{Introduction}

The propagation of low frequency electromagnetic waves within the cavity formed by two highly conductive spherical shells, such as the surface and the ionosphere of Earth, was first studied by Schumann (1952) and subsequently observed by Balser and Wagner (1960). When a cavity is excited with an electromagnetic source, resonant states develop, where the average equatorial circumference of the cavity is approximately equal to integral numbers of the signal wavelengths. This phenomenon, known as the Schumann resonance, is the signature of thunderstorm and lightning activities, and is sometimes coined "the global tropical thermometer" (Williams, 1992). This subject is not only related to lightning activity, but also to climatology, to coupling mechanisms between ionosphere, magnetosphere and solar wind, and, to a lesser extent, to investigations of the subsurface at shallow depths, using the transverse resonant mode (Guglielmi and Pokhotelov, 1996; Nickolaenko and Hayakawa, 2002).

The same formalism has been used for the cavities of other celestial bodies, such as Mars (e.g. Molina-Cuberos et al., 2006) and Titan (e.g. Simões et al., 2007). Simpler approaches have sometimes been applied to other bodies, Venus, Jupiter, and Io (Nickolaenko and Rabinovich, 1982; Sentman, 1990). There are important differences between the characteristics of these cavities, namely the reflectivity of the surface, the radius of the inner shell $\left(R_{\text {int }}\right)$, the altitude of the ionosphere $(h)$, the atmospheric electron density profile, the nature and distribution of the electromagnetic sources. In a first approximation, the inner radius of the cavity defines the frequencies of the Schumann resonances, which lies in the extremely low frequency (ELF) range; taking into account the other features of the cavities brings in first and second order corrections that tend to decrease the frequencies. Atmospheric conductivity induces losses that attenuate the propagating waves; if the conductivity is large enough, the waves are evanescent and no resonant state develops. 
On Earth, lightning activity pumps energy into the cavity but other phenomena do also contribute. Charge generation and separation produce lightning-like electrical sparks, hundreds of meters long, during volcanic eruptions (Rakov and Uman, 2003). Triboelectric charging within a turbulent particle flow produces discharges (Farrell and Desch, 2001). Hydromagnetic waves may also contribute to the excitation of the Schumann modes (Abbas, 1968). The same mechanisms will generate electromagnetic radiation in the cavities of other planets and satellites. In dry atmospheres, like that of Mars, dust devils and dust storms may induce electrical discharges (Aplin, 2006). A similar assumption can be made about the cavity of Titan, where haze and charged aerosols, and a significant conductivity, could also play a role.

The boundaries of the cavity are located where the skin depth of the propagating waves is much smaller than the separation between the shells. On Earth, the inner $\left(R_{\text {int }}\right)$ and outer $\left(R_{\text {ext }}\right)$ boundaries coincide with the planet's surface and the lower limit of the ionosphere. The conductivity of the surface is the order of 0.01 and $1 \mathrm{Sm}^{-1}$ on land and sea, respectively (Lide 2006), and the perfect electric conductor (PEC) approximation applies. The skin depth in the Chapman layer is several orders of magnitude smaller than that in the atmosphere and the lower boundary of the ionosphere acts as a perfect reflector for ELF waves. The definition of the boundaries, especially the inner boundary, is less straightforward in other environments and has to be analyzed case-by-case. On Venus, for example, the surface can be considered as the inner shell of the cavity only if the soil conductivity is larger than $10^{-4} \mathrm{Sm}^{-1}$, but this assumption is not valid on Titan, where the surface conductivity is extremely low. The cavities of the giant planets are even more mysterious because they have no well-defined surface, and modeling their characteristics is a significant challenge. The cavity generally consists of the atmosphere, up to the ionosphere, and of the solid outer layer of the body, when the conductivity of the subsurface material is small enough. On Earth, the skin depth at 
the surface for ELF is less than $1 \mathrm{~km}$, but the situation is quite different on Titan and possibly on the giant planets.

The cavity of Titan is particularly interesting. The electron density profile is known to some extent in the lower atmosphere (Hamelin et al., 2006); the soil at the Huygens Probe landing site is similar to a good dielectric (Grard et al., 2006), at least at shallow depths, and the skin depth is large. Several models predict the presence of a subsurface ocean, possibly a waterammonia mixture (Lunine and Stevenson, 1987; Sohl et al., 1995; Tobie et al., 2005), and the study of wave propagation in the cavity might provide some indications about the depth of the solid-liquid interface (Simões et al., 2007).

In this paper, we review the propagation process of ELF waves in planetary cavities, and estimate eigenfrequencies and Q-factors with a finite element model especially developed for Titan. This approach is novel and brings in several improvements: (a) the technique is applicable not only to Earth but also to other planets; (b) the conductivity profile within the cavity is arbitrary; (c) the subsurface can be explored when the surface of the body is not the inner boundary of the cavity; (d) the conductivity profile is sensitive to water content and information about the atmospheric composition of the giant planets can be derived. We present results obtained for recent models of the giant planets and assess the role played by the dielectric properties of their subsurface. Finally, we review the scientific significance of the Schumann resonance and briefly describe the technical requirements associated with its observation.

\section{Wave Propagation in the Cavity}

The Schumann eigenfrequencies are derived from the resonance condition of a cavity. The resonant angular frequency of a thin spherical cavity is written (Schumann, 1952)

$$
\omega_{n}=\sqrt{n(n+1)} \frac{c}{R}
$$


where $n$ is an integer that identifies the eigenmode, $c$ the velocity of light in the medium and $R$ the average radius of the cavity. In addition to the longitudinal modes that are functions of the cavity radius, there exist local transverse modes along the radial direction. When the spherical shells that form the cavity are PEC's, the transverse mode requires that the electric field be zero on the boundaries. A resonance develops whenever the distance between the shells, generally the height of the ionosphere, $h$, is an integer number, $p$, of half-wavelengths,

$$
\omega_{p}=p \frac{c \pi}{h}
$$

The analytical approximations are usually solved by decoupling the longitudinal and transverse modes, which is a fair approximation when the height of the ionosphere is much smaller than cavity radius, i.e. $h / R<<1$. This condition is applicable, for example, to Earth and Venus but not to Titan.

The full treatment of the Schumann resonance in the cavity requires the solution of Maxwell equations

$$
\begin{aligned}
& \nabla \times \boldsymbol{E}=-\frac{\partial \boldsymbol{B}}{\partial t} \\
& \nabla \times \boldsymbol{H}=\sigma \boldsymbol{E}+\frac{\partial \boldsymbol{D}}{\partial t}
\end{aligned}
$$

with

$$
\boldsymbol{D}=\varepsilon \varepsilon_{o} \boldsymbol{E}, \quad \boldsymbol{B}=\mu_{o} \boldsymbol{H},
$$

where $\boldsymbol{E}$ and $\boldsymbol{D}$ are the electric and displacement fields, $\boldsymbol{H}$ and $\boldsymbol{B}$ are the magnetic field strength and flux density, $\varepsilon_{o}$ and $\mu_{o}$ are the permittivity and magnetic permeability of vacuum, and $\sigma$ and $\mathcal{E}$ are the conductivity and the relative permittivity of the medium.

The system of Eq.s (03)-(05), together with the cavity constraints, can be solved analytically in spherical coordinates, using the harmonic propagation approximation and decoupling the electric and magnetic fields. One mode is characterized by $H_{r}=0$ and is called transverse magnetic (TM) wave, the other one by $E_{r}=0$ and is known as the transverse electric (TE) 
wave. However, many approximations used for the Earth cavity, where the condition $h / R<<1$ is valid, are not applicable to other environments (Simões et al., 2007).

Unlike that of Earth, the surfaces of several other bodies offer larger losses due to their lower reflectivity. The most typical example is Titan, whose surface conductivity is extremely low, $\sigma_{\text {surf }} \sim 10^{-10} \mathrm{Sm}^{-1}$, as measured by the Huygens Probe (Grard et al., 2006). An intermediate situation should be encountered on Venus and Mars. Propagation below the surface and wave attenuation are related to the skin depth, $\delta$, by (Balanis, 1989)

$$
\delta=\sqrt{\frac{2}{\mu_{o} \varepsilon_{o}}} \frac{\left(\sqrt{1+\left(\frac{\sigma}{\omega \varepsilon_{o}}\right)^{2}}-1\right)^{-1 / 2}}{\omega},
$$

where $\omega$ is the angular frequency. These considerations are of course not relevant when the surface satisfies the PEC condition.

The quality factor is another useful parameter since it partly controls the wave attenuation in the cavity. This quantity is defined by the ratio between the real and the imaginary parts of the eigenfrequencies

$$
Q_{m} \equiv \frac{\operatorname{Re}\left(\omega_{m}\right)}{2 \operatorname{Im}\left(\omega_{m}\right)} \approx \frac{\omega_{m}^{\text {peak }}}{\Delta \omega_{m}}
$$

where $R e$ and $I m$ are the real and imaginary parts of the complex eigenfrequency, and $\Delta \omega_{m}$ is the width at half-power level of the line with peak frequency $\omega_{m}{ }^{\text {peak }}$ and mode $m$. The Q-factor measures the ratio of the accumulated field power to the power lost during one oscillation period; $Q \propto \omega / \alpha$ is inversely proportional to the absorption coefficient, $\alpha$, and characterizes the propagation conditions in the cavity. The absorption coefficient quantifies the rate at which power decreases with distance. An expedient way of estimating the quality factor consists, in a first approximation, in using instead the ratio between the resonator height and the skin depth of the electric field, $Q \propto h / \delta$ (Nickolaenko and Hayakawa, 2002). It is seen that 
increasing the ionosphere height augments the quality factor, whereas the larger skin depth of a poorly conducting boundary amplifies the losses in the cavity.

\section{The Numerical Approach}

The numerical model uses the finite element method (Zimmerman, 2006) for solving Eq.s (03)-(05) with specific boundary conditions and medium properties. The algorithm calculates the eigenfrequency, Q-factor, and electromagnetic field distribution in the cavity. The numerical model is validated by comparing the eigenfrequencies given by the finite element model with theoretical approximations for the Earth cavity. The validation procedure and the model sketched in Fig. 1 are further discussed by Simões et al. (2007) in the case of Titan. For the sake of clarity, we define the interior of the gaseous giants as the region where the pressure is larger than 1 bar and this reference level determine the radius of the planet. The parameters that play a major role are listed below:

a) Conductivity profile of the atmosphere and lower ionosphere $\left(\sigma_{\text {atm }}\right)$. The conductivity is derived from the electron density and collision frequency profiles, obtained from pressure, temperature and atmospheric composition data.

b) Permittivity profile of the atmosphere and lower ionosphere $\left(\varepsilon_{a t m}\right)$. The permittivity is a weak function of atmospheric gas density and does not significantly deviate from that of vacuum, even for Venus.

c) Depth of the inner boundary $(d)$. This parameter gives the depth of the inner PEC boundary; $d=0$ at Earth, because the surface is a good reflector.

d) Conductivity profile of the interior $\left(\sigma_{\text {int }}\right)$. The subsurface conductivity of Earth is not relevant, but this is not necessarily true for other rocky bodies, whose soil properties play an important role. However, the variation of conductivity with depth is difficult to assess. 
Theoretical models predict that the conductivity of the gaseous giants should increase with depth, in different ways for Jupiter and Saturn, and for Uranus and Neptune.

e) Permittivity profile of the interior $\left(\varepsilon_{\text {int }}\right)$. The relative permittivity of the interior of the rocky planets is considered constant with depth and of the order of 3 and 5-10 for icy and rocky soils, respectively. The permittivity of the interior of the giant planets should increase with depth and density. The relative permittivity of liquid hydrogen is $\sim 1.25$ (Lide 2006). Therefore, the relative permittivity of the gaseous envelope is assumed to increase with depth in the range 1-1.25, reaching its maximum at the solid (Uranus and Neptune) or liquid (Jupiter and Saturn) interface.

[Place Figure 1 here]

\section{Cavity Parameterization}

The various cavity environments encountered in the Solar System can be grouped in two major classes: (1) partly rocky/icy and (2) entirely gaseous cavities. By definition, the radius of the gaseous planets is determined by the 1-bar reference surface that is of little interest for our purpose. We shall now describe the models and compute the eigenfrequencies and Qfactors for Venus; Earth; Mars; Jupiter and Saturn; Titan, Europa and Io; Uranus and Neptune.

\subsection{Venus}

Our knowledge of Venus has been gained from ground-based observations, and orbiter flyby, balloon and lander space missions. The properties of the upper ionosphere are measured with propagation techniques during radio occultation, but the electron density in the lower ionosphere and atmosphere is not known. Data from several missions, such as Voyager and Pioneer Venus (Brace et al., 1997) are available, but the conductivity of the atmosphere (Fig. 
2b) is inferred from theoretical models (Borucki et al., 1982). The carbon dioxide mole fraction of the atmosphere of Venus is $\sim 0.965$ and the minimum altitude of the sulphuric acid clouds is $\sim 57 \mathrm{~km}$. Lightning activity continues to be a controversial issue. The atmospheric pressure increases the breakdown voltage and prevents cloud-to-ground discharges but phenomena analogue to terrestrial sprites are possible (Strangeway, 2004).

The temperature and pressure profiles of the atmosphere were provided by the Pioneer Venus probes and properties of the surface by the Venera landers and Magellan. A surface temperature and a pressure of the order of $750 \mathrm{~K}$ and 92 bars, respectively, yield an atmospheric density about 54 times that on Earth. The relative permittivity is $\sim 1.05$ at the surface level and does not significantly affect the eigenfrequencies. The permittivity profile of the atmosphere, that is a function of density, is plotted in Fig. 2 b.

Volcanic processes, and many constructs and plains covered with extensive lava flows, dominate the surface of Venus. The radar altimeter onboard Pioneer Venus (Pettengill et al., 1988) has shown that the radar-bright spots could be explained either by roughness with a scale commensurate with the wavelength of the mapping signal, or by a larger dielectric constant of the surface material due to the presence of moderately conductive minerals such as iron sulfides and oxides. The radar imager onboard Pioneer Venus measured the surface relative permittivity; the average over the rolling plains and the lowlands is $5.0 \pm 0.9$, and suggests that the surface is overlaid with a few $\mathrm{cm}$ of soil or dust. There is no evidence of significant water vapor concentration in the atmosphere and on the surface. The soil should possess the dielectric properties of a dry igneous medium, such as basalt, at $\sim 750 \mathrm{~K}$. The relative permittivity considered in the model is of the order of $4-10$; the conductivity is assumed to lie in the range $10^{-4}-10^{-6} \mathrm{Sm}^{-1}$, based on the values observed on Earth for the same composition and temperature range (Shanov et al., 2000; Lide 2006). The conductivity profile (Fig. 2a) is a function of the interior temperature (Arkani-Hamed, 1994) in the depth range 0- 
$150 \mathrm{~km}$. The dielectric parameters are not dramatically different if high silica content is considered, and the soil permittivity does not play a role because the conductivity is sufficiently large.

[Place Figure 2 here]

\subsection{Earth}

Schumann has studied the propagation of ELF electromagnetic waves in the cavity of Earth and estimated its resonant frequencies. Subsequent research on the topic has identified lightning activity as the major source of energy, and revealed the role of many factors: daynight asymmetry of the ionosphere, climate variability, influence of the solar wind on the upper boundary, etc. The correlation between the distribution of thunderstorms and the occurrence of the Schumann resonance in the cavity provides information about atmospheric activity. The work of Nickolaenko and Hayakawa (2002), and hundreds of references therein, testify the importance of this topic. With the exception of the phenomenon recorded during the descent of the Huygens Probe through the atmosphere of Titan (Simões et al., 2007), which is still under investigation, the Schumann resonance has never been identified so far on any celestial body but Earth.

Earth is used for the validation of the finite element model because the relevant parameters, permittivity, conductivity, and boundary conditions, are known with a fair accuracy, and the Schumann resonance has been extensively studied experimentally (e.g. Sentman, 1995). The average Schumann frequencies and Q-factors are 7.9, 14, and $20 \mathrm{~Hz}$ and 4, 4.5, and 5, respectively, for the three lowest eigenmodes. 


\subsection{Mars}

Although many missions have been flown to Mars, electron density measurements are available for the ionosphere only (e.g. Fjeldbo et al., 1977; Pätzold et al., 2005). Theoretical models are therefore used to extend the conductivity profile down to the surface (Cummer and Farrell, 1999; Pechony and Price, 2004; Molina-Cuberos et al., 2006). Different profiles are found in the literature and, in some instances, ELF wave propagation is questionable due to strong cavity losses. We shall use the conductivity profile shown in Fig. 3. The atmosphere consists mostly of $\mathrm{CO}_{2}$, with a mole fraction of $\sim 0.953$; the atmospheric density is about 70 times less than on Earth and the permittivity is very close to that of vacuum.

\section{[Place Figure 3 here]}

The Martian environment has been studied using Earth-based, remote sensing, and in situ observations, but the electrical properties of the surface are still poorly known. Theoretical models yield conflicting results for surface conductivity and permittivity. According to Christensen and Moore (1992), the relative permittivity of the regolith lies in the range 2.412.5 , but no figure is given for that of the subsurface. The conductivity of the surface is also poorly defined and estimates vary between $10^{-7}$ and $10^{-12} \mathrm{Sm}^{-1}$ in the literature. Berthelier et al. (2000) tentatively restrict the range down to $10^{-10}-10^{-12} \mathrm{Sm}^{-1}$. Contrasting compositions are seen at low and high latitudes, due to the presence of ice deposits in the polar regions. The subsurface dielectric properties of the regolith should vary with depth and composition, especially if water/ice/brines are embedded in the medium. We shall assume that the dielectric constant and conductivity of the soil are homogeneous with depth and lie in the ranges 4-10 and $10^{-7}-10^{-12} \mathrm{Sm}^{-1}$, respectively.

There is no evidence of lightning activity on Mars but it is generally accepted that, due to triboelectric effects, massive dust storms might enhance atmospheric electrification, in 
particular in dust devils, as simulated on Earth (Krauss et al., 2003; Farrell and Desch, 2001). The spectral features of these emissions should however considerably differ from those observed in the Earth cavity.

\subsection{Jupiter and Saturn}

The atmospheres of the Jovian planets are mainly composed of hydrogen and helium (the mean concentrations are $\mathrm{H}_{2}: 0.82$ and 0.94 , and He: 0.18 and 0.06 , for Jupiter and Saturn, respectively) with much lower mole fractions for other components, such as methane, ammonia and water vapor. The pressure and temperature profiles are given by Justus et al. (2005). The atmospheric density increases drastically with depth and the vacuum approximation is no longer valid for the permittivity. Deep in the molecular hydrogen envelope, the density increases beyond the gaseous phase threshold and a liquid environment is expected. The permittivity therefore increases with depth until it reaches the value of liquid hydrogen, which is $\sim 1.25$. The permittivity profiles shown in Fig. 4 are derived from the interior density models of the Jovian planets (e.g. Lewis, 1995). The normalized radii of the solid-liquid interfaces are $\sim 0.76$ and $\sim 0.48$ for Jupiter and Saturn, respectively.

\section{[Place Figure 4 here]}

The conductivity profile of the interior (Fig. 5) is adopted from a theoretical model developed by Liu (2006). The conductivity of the atmosphere is derived from the electron density, pressure, temperature, and composition data collected by several spacecraft. The conductivity of the lower atmosphere is interpolated between that of the lower ionosphere and that of the upper interior (Fig. 5-6). Majeed et al. (2004) present an overview of the ionospherethermosphere of the giant planets, which is a useful reference for comparison. 
Lightning activity is present on Jupiter and Saturn; it has been observed with Voyager 1, Galileo and Cassini (Gurnett et al., 1979; Lanzerotti et al., 1996; Fischer et al., 2006) and is probably the major source of energy.

[Place Figure 5 here; Place Figure 6 here]

\subsection{Titan, Europa and Io}

This work deals not only with planets but also with a few moons. Titan, Europa, and Io environments are all different and unique. Therefore, studying the propagation of ELF waves and the resonance that can develop in their cavities is an interesting exercise.

The conductivity profile of the atmosphere of Titan was directly measured with mutual impedance and relaxation probes during the descent of the Huygens Probe from an altitude $\sim 140 \mathrm{~km}$ down to the surface (Hamelin et al., 2006). The conductivity is unknown at higher altitude, up to $\sim 750 \mathrm{~km}$ where Voyager and Cassini spacecraft have measured the electron density (e.g. Wahlund et al., 2005). The conductivity profile (Fig. 7) is therefore interpolated between 140 and $750 \mathrm{~km}$, in an altitude range where aerosols play a significant role. The atmospheric density on the surface is $\sim 4.5$ times that on Earth, thus the vacuum approximation is valid for the permittivity. As already mentioned, the relative permittivity and conductivity at shallow depths are $\sim 2$ and $\sim 10^{-10} \mathrm{Sm}^{-1}$ at the Huygens Probe landing site (Grard et al., 2006). The variation of the dielectric parameters with depth is not known but some general assumptions can be made. The temperature of the soil varies between $\sim 94 \mathrm{~K}$ on the surface and $\sim 176 \mathrm{~K}$ at the solid-liquid interface, as suggested by theoretical models (Grasset and Sotin, 1996). In this temperature range the dielectric properties of water ice do not vary significantly, even in the ELF frequency range. Several models predict the presence of water-ammonia ice mixtures (Lunine and Stevenson, 1987; Tobie et al., 2006) and the dielectric properties are more difficult to assess. The composition and porosity of the soil are 
unknown but a relative permittivity in the range 2-4 is tentatively assumed, which fits that of water ice in the considered temperature and frequency ranges. The concentrations of ionic contaminants are not known and even small quantities can significantly increase the conductivity of the medium.

\section{[Place Figure 7 here]}

The existence of an ionospheric layer and, therefore, of a cavity does not necessarily imply that Schumann resonances develop. The Jovian moons, Io and Europa, possess an ionosphere (Kliore et al., 1974; Kliore et al., 1997) and, alike for Titan, models also predict the existence of a subsurface ocean on Europa, the moon that displays the smoothest surface in the Solar System. However, the electron density in the thin atmosphere of Europa is such that it prevents the development of resonant states, and the subsurface cannot be explored with ELF waves. In fact, the conductivity is high and ELF waves are damped. The subsurface of this Galilean satellite can however be accessed in another way. The electrical conductivity of the ionosphere and interior prevents the penetration of the time varying fraction of the external magnetic field, a phenomenon that should in principle reflect the presence of an ocean beneath the surface (Russell, 2000). On Io, volcanic activity is a likely source of energy, but as for Europa, only evanescent waves can be produced because of the high conductivity of its thin atmosphere.

\subsection{Uranus and Neptune}

The cavities of the Uranian planets are quite different from those of Jupiter and Saturn. Their atmospheres are essentially composed of hydrogen and helium $\left(\mathrm{H}_{2}: 0.74\right.$ and 0.68 , He: 0.26 and 0.32 for Uranus and Neptune, respectively) and the molar fractions are closer to solar abundances than those of the other gaseous giants. Voyager 2 measured the electron density (Lindal et al., 1987; Lindal 1992) with some discrepancy between ingress and egress, 
especially in the case of Uranus. Two conductivity profiles are derived for Uranus from the Voyager data sets, based on analogy with Earth and on modeling; in the case of Neptune a single profile is used (Capone et al. 1977; Chandler and Waite, 1986). The eigenfrequencies are not much affected by uncertainties about the atmospheric conductivity because the subsurface contribution is dominant.

The interior of Uranus and Neptune significantly differs from that of the Jovian planets. A solid mantle of ices is substituted for the liquid hydrogen metallic mantle of Jupiter and Saturn. Discontinuities in the permittivity profile and in the derivative of the conductivity profile are expected at the solid-gaseous interface (Liu, 2006). The profiles (Fig. 8-10) are evaluated in the same way as for the Jovian planets. The water content of the Uranian planets is unknown and a concentration of only a few percent could increase the conductivity by orders of magnitude.

[Place Figure 8 here; Place Figure 9 here; Place Figure 10 here]

As for the Jovian planets, though in a less degree of confidence, the Voyager 2 measurements indicate that lightning activity is the major source of electromagnetic energy in the cavities of Uranus and Neptune (Zarka and Pedersen, 1986; Gurnett et al., 1990).

\section{Numerical Results}

Table 1 recapitulates the main geometrical features of the cavities and the corresponding fundamental eigenfrequencies calculated with Eq. (01), where most radii are estimated from osculating orbital data (Woan, 1999). All eigenfrequencies lie about the ELF range; the result given for Titan is less accurate because the relative thickness of its cavity is significantly larger than for the planets. The most probable sources of electromagnetic energy in each cavity are listed in Table 2.

[Place Table 1 here; Place Table 2 here] 
Table 3 shows the numerical results obtained for the different bodies using the finite element method with, in some cases, several cavity configurations. The values obtained by other authors with analytic, semi-analytic and numerical approaches, are also listed for the sake of comparison. Though comparison between our model and other approaches is sometimes difficult or inappropriate, we present a global analysis of the different models. The first conclusion is that analytic and semi-analytic approximations produce less accurate results. However, other interpretation can be made:

a) Venus - a vacuum approximation for the cavity only provides a rough estimation of the eigenfrequencies (Guglielmi and Pokhotelov, 1996); the model mentioned by Nickolaenko and Hayakawa (2002) produces more accurate results with particular surface conditions; Alike the present model, Pechony and Price (2004) have used Borucki et al. (1982) atmospheric conductivity profile (Fig. 2b) and obtained larger eigenfrequencies, indicating that surface losses play an important role in wave propagation.

b) Earth - the numerical model is validated (Simões et al., 2007) with an experimental conductivity profile and reproduces the measured eigenfrequencies (Nickolaenko and Hayakawa, 2002); however, the computed Q-factors are slightly higher than the experimental values.

c) Mars - the models of Sukhorukov (1991) and Molina-Cuberos et al. (2006) give higher frequencies than the results of Pechony and Price (2004); the present model uses the same conductivity profile as Pechony and Price (2004) and the results are similar because the PEC boundary depth is small.

d) Jupiter - Rough estimations using Eq. (01) have been calculated by Guglielmi and Pokhotelov (1996) and Nickolaenko and Hayakawa (2002); however, the model developed by Sentman (1990) that places the lower boundary deeper in the planet provides closer results to those of the present model. 
e) Titan - The model of Nickolaenko et al. (2003) predicts a large value for the Schumann resonance, based on a particular conductivity profile. Morente et al. (2003) and Yang et al. (2006) employ different numerical models, transmission line modeling and finite difference time domain respectively, but the same conductivity profile (Molina-Cuberos et al., 2004). According to Yang et al. (2006), the difference between the results is due to the various altitudes adopted for the upper boundary. This hypothesis has been confirmed by Simões et al. (2007) using the present finite element model; improved results taking into account a more realistic conductivity profile based on results from the Cassini-Huygens mission are also reported.

f) Saturn, Uranus and Neptune - no reference has been found regarding the Schumann resonance in these environments.

All cavities are unique; and must be explored in different ways. Comparing their properties within each group, i.e. rocky/icy bodies and giant planets, is nevertheless quite instructive. For example, the Q-factors and absorption coefficients are derived from the real and imaginary parts of the eigenfrequencies given in Table 3; they provide an insight into the wave propagation conditions in each group of cavities.

On Venus, the nature of the surface drives the quality factor of the cavity $(\mathrm{Q}>5)$, which is larger than on Earth for several cavity configurations. When the soil conductivity decreases, the losses are larger and the eigenfrequency and Q-factor are reduced, but this effect is small if the conductivity is larger than $10^{-4} \mathrm{Sm}^{-1}$. The atmospheric conductivity profile at low altitude is unknown but the high neutral density of the atmosphere prevents cavity losses from playing a significant role in ELF wave propagation. In fact, wave attenuation at altitudes below $\sim 40 \mathrm{~km}$ can be neglected, like in the Earth cavity.

[Place Table 3 here] 
Contrary to the surface of Venus, whose dielectric properties are assumed to be uniform, the Martian regolith appears complex and asymmetric. The ice caps are mostly composed of water ice (Bibring et al., 2004); hence, the surface conductivity is larger at the poles than in the equatorial regions. The models also predict that the regolith is highly depleted in water ice at low latitudes, and that liquid water should be found at a depth increasing from 2 to $10 \mathrm{~km}$, between the equator and the poles (Squyres et al., 1992); the conductivity should therefore vary with depth and latitude. The presence of water and brines should introduce major changes on the reflectivity coefficient. Estimates of the surface conductivity lie in the range $10^{-7}-10^{-12} \mathrm{Sm}^{-1}$. Uncertainties about the subsurface stratigraphy and water content limit our understanding of wave propagation. Several options are therefore considered: PEC on the surface (unlikely); subsurface reflector at 5 and $10 \mathrm{~km}$; subsurface conductivity of $10^{-7}$ and $10^{-10} \mathrm{Sm}^{-1}$; permittivity in the range $5-10$. It is anticipated that the dielectric properties vary with depth and temperature, but it is difficult to quantify this effect. Temperature should nevertheless have a second order effect, compared to surface conductivity.

The eigenfrequencies of a Martian cavity with high atmospheric conductivity significantly differ from those calculated with lossless approximation. Wave attenuation is stronger than on Earth and the absorption coefficient is, at least, twice as large. Contrary to expectations, the absence of a perfect reflector on the surface does not necessarily imply higher losses in the cavity. In fact, several parameters have contrasting effects; a larger conductivity increases the losses and a larger permittivity shifts the eigenmodes towards lower frequencies, but a lower cavity radius increases the eigenfrequencies.

Titan has a peculiar environment. A peak in electron density at $\sim 60 \mathrm{~km}$ splits the cavity in two concentric shells, and the presence of aerosols influences the propagation of the waves in the cavity (Table 3 ). The surface low conductivity may lead to the identification of the subsurface liquid ocean predicted by theoretical models. The high concentration of aerosols in the 
atmosphere increases the extinction coefficient in the infrared and visible domains though it has contrasting effects at low frequencies. In fact, electron attachment to aerosols reduces the atmospheric conductivity and, consequently, also the absorption coefficient. However, the conductivity profile becomes more intricate due to aerosol stratification. Depending upon aerosol concentration, the absorption coefficients and the Q-factors resemble either those of Earth or those of Mars.

The cavities of the gaseous giants are characterized by a smooth transition between the atmosphere and the interior, and the effective inner boundary is located where the skin depth is much smaller than the cavity thickness. In the case of the Jovian planets the effective inner boundary is significantly larger than the gas-liquid interface radius. The quality factors for Jupiter and Saturn, Q 8, are larger than for Earth. The situation differs for the Uranian planets, where several theoretical models are compatible with high or low water content. The absence of water implies large quality factors, of the order of 20 and 10 for Uranus and Neptune, respectively, and increases the Schumann resonance frequencies by a factor of two compared to cavities with high water content. When the water content in the gaseous envelope is $\sim 15 \%$, the Q-factor is reduced by one order of magnitude, the absorption factor increases and wave propagation is hindered.

In the present study, we have neglected several factors that can play an important role, such as the day-night asymmetry and the presence of an intrinsic magnetic field. These contributions are discussed in a forthcoming paper essentially dedicated to Venus.

\section{Instrumentation}

Instruments that measure electric and magnetic fields in the ELF range provide the measurements from which the eigenfrequencies and Q-factors of the cavity are calculated. These data yield information about the cavity environment: electromagnetic sources, 
conductivity profile and, in some circumstances, atmospheric composition and subsurface properties.

Like on Earth, the main field components are the vertical (radial) electric and horizontal (azimuthal) magnetic fields. The electric field component can be measured with a vertical dipole antenna. The horizontal component of the magnetic field can be detected with loop antennas. Magnetic antennas usually possess a core, but it is possible to use large loop antennas with multiple turns (Polk, 1969; Burrows, 1978). The output voltage of the magnetic antenna is proportional to the magnetic induction and loop effective area. It is important to avoid mechanical vibrations or ensure, at least, that their frequencies do not fall within the ELF range. An external electrostatic field can easily induce an electric signal in a vibrating antenna and mask the Schumann resonance signal (Béghin et al., 2007). Vehicle vibrations induced by air flow are also observed during balloon campaigns devoted to atmospheric electricity. It is easier to measure Schumann resonances in a steady state than during ascent or descent. Electrostatic and ELF electromagnetic noise decrease instrument sensitivity and limit the measurement threshold to about a fraction of $1 \mathrm{mV}$. Static modules on the surface or atmospheric vehicles floating at a constant altitude minimize turbulence and antenna vibrations.

The architecture of the antenna is necessarily constrained by the type of mission, namely lander, balloon or descent probe. In the case of surface probes, such as static structures or rovers, a mast is probably most convenient (e.g. Berthelier et al., 2000). For buoyant probes such as balloons and airships, other configurations may be preferred, e.g. flexible magnetic loops attached to - or embedded in - the structure of the vessel, or booms attached to a gondola, as on the Huygens Probe (Grard et al., 1995). Recording the waveform facilitates the data analysis but an onboard spectral processing is generally more convenient due to memory constraints. On Earth, during strong lightning activity and in controlled experimental 
conditions, up to 13 peaks associated with the Schumann resonance have been identified (Füllekrug, 2005). During stratospheric balloon campaigns, we have observed 7 peaks in a quiet environment at a constant altitude, but only 2 during ascent, which confirms that the vessel trajectory and dynamics impose significant constraints on the measurement.

\section{Conclusion}

The propagation of ELF electromagnetic waves has been extensively studied in the cavity of Earth, where lightning activity is the major energy source. The same approach can be used for other planetary environments. At present, lightning activity has undoubtedly been detected on Earth, Jupiter and Saturn; it is likely on Uranus and Neptune, and possible on Venus and Titan.

The Schumann resonance has been identified only on Earth. The Titan in-situ measurements performed by the Huygens Probe are still under investigation and should confirm whether ELF resonances have been observed or not (Simões et al., 2007). This work recapitulates the models and predictions that have been published for Venus, Mars, Jupiter, Io, and Titan, and extends them to other planets, namely Saturn, Uranus, and Neptune.

Unlike most previous techniques that are based on analytical and semi-analytical approximations, we use a 3D finite element model that includes losses not only in the atmosphere and ionosphere, but also below the surface. Several authors have already proposed the utilization of the Schumann resonance as a tool for investigating the inner boundary of the ionosphere. This work also discusses the suitability of the Schumann resonance for sounding the subsurface of planets and satellites to an appreciable depth when the soil conductivity is lower than $\sim 10^{-6} \mathrm{Sm}^{-1}$.

Whenever resonant states develop in planetary cavities, the measurement of Schumann resonance provides useful information about wave propagation conditions. In the case of the 
rocky planets, Venus and Mars, the contribution of the subsurface brings a minor correction to the eigenfrequencies (Table 3) and, therefore, accurate measurements are required in order to extract any information about the soil properties. A different scenario might occur in the cavities of the giant planets, mainly Uranus and Neptune.

According to theoretical models, the conductivity of the gaseous envelope of the Uranian planets is strongly dependent on the water/ice content. Besides, the conductivity of waterdepleted and water-rich $(\sim 10-15 \%)$ atmospheres may differ by as much as 10 orders of magnitude, which significantly changes wave propagation conditions. In fact, the presence of water in the atmosphere can easily divide the eigenfrequencies by a factor of two (Table 3); the Schumann resonance could therefore be a valuable tool for probing the conductivity profile and, indirectly, estimating the water mixing ratio of the gaseous envelope.

\section{Acknowledgements}

The first author is indebted to Alain Péan for fruitful discussions about software and hardware optimization. 


\section{References}

Abbas, M. 1968. Hydromagnetic wave propagation and excitation of Schumann resonances. Planet. Space Sci. 16, 831-844.

Aplin, K.L. 2006. Atmospheric electrification in the Solar System. Surv. Geophy. 27, 63-108.

Arkani-Hamed, J. 1994. On the thermal evolution of Venus. J. Geophys. Res. 99, 2019-2033.

Balanis, C.A. 1989. Advanced Engineering Electromagnetics. Wiley, New York.

Balser, M., Wagner, C.A. 1960. Observations of Earth-ionosphere cavity resonances. Nature, $188,638-641$.

Béghin, C. Simões, F. Karsnoselskhikh, V. Schwingenschuh, K. Berthelier, J.J. Besser, B. Bettanini, C. Grard, R. Hamelin, M. López-Moreno, J.J. Molina-Cuberos, G.J., Tokano, T. 2007. A Schumann-like resonance on Titan driven by Saturn's magnetosphere possibly revealed by the Huygens probe. Icarus, doi:10.1016/j.icarus.2007.04.005.

Berthelier, J.-J., Grard, R., Laakso, H., Parrot, M. 2000. ARES, atmospheric relaxation and electric field sensor, the electric field experiment on NETLANDER. Planet. Space Sci. 48, 1193-1200.

Bibring, J.-P., Langevin, Y., Poulet, F., Gendrin, A., Gondet, B., Berthé, M., Soufflot, A., Drossart, P., Combes, M., Bellucci, G., Moroz, V., Mangold, N., Schmitt, B., OMEGA team. 2004. Perennial water ice identified in the south polar cap of Mars. Nature, 428, 627-630. 
Borucki, W.J., Levin, Z., Whitten, R.C., Keesee, R.G., Capone, L.A., Toon, O.B., Dubach, J., 1982. Predicted electrical conductivity between 0 and $80 \mathrm{~km}$ in the Venusian atmosphere. Icarus, 51, 302-321.

Brace, L. H., Grebowsky, J. M., Kliore, A. J. 1997. Pioneer Venus orbiter contributions to a revised Venus reference ionosphere. Adv. Space Res. 19, 1203-1212.

Burrows, M.L. 1978. ELF communications antennas. Peter Peregrinus, London, UK.

Capone, L.A., Whitten, R.C., Prasad, S.S., Dubach, J. 1977. The ionospheres of Saturn, Uranus, and Neptune. Astrophys. J. 215, 977-983.

Chandler, M.O., Waite, J.H. 1986. The ionosphere of Uranus - A myriad of possibilities. Geophys. Res. Lett. 13, 6-9.

Christensen, P. R., Moore, H. J. 1992. The Martian surface layer. In: Kieffer, H.H., Jakosky, B.M., Snyder, C.W., Matthews, M.S. (Eds.), Mars, Univ. of Arizona Press, Arizona, pp. 686729.

Cummer, S. A., Farrell, W. M. 1999. Radio atmospheric propagation on Mars and potential remote sensing applications. J. Geophys. Res. 104, E6, 14149-14158.

Farrell, W. M., Desch, M. D. 2001. Is there a Martian atmospheric electric circuit? J. Geophys. Res. 106, 7591-7595. 
Fjeldbo, G., Sweetnam, D., Brenkle, J., Christensen, E., Farless, D., Mehta, J., Seidel, B., Michael Jr., W., Wallio, A., Grossi, M. 1977. Viking radio occultation measurements of the Martian atmosphere and topography - Primary mission coverage. J. Geophys. Res. 82, 43174324.

Fischer, G., Tokano, T., Macher, W., Lammer, H., Rucker, H. O. 2004. Energy dissipation of possible Titan lightning strokes. Planet. Space Sci. 52, 447-458.

Fischer, G., Desch, M. D., Zarka, P., Kaiser, M. L., Gurnett, D. A., Kurth, W. S., Macher, W., Rucker, H. O., Lecacheux, A., Farrell, W. M., Cecconi, B. 2006. Saturn lightning recorded by Cassini/RPWS in 2004. Icarus 183, 135-152.

Grard, R., Svedhem, H., Brown, V., Falkner, P., Hamelin, M. 1995. An experimental investigation of atmospheric electricity and lightning activity to be performed during the descent of the Huygens Probe on Titan. J. Atmos. Terr. Phys. 57, 575-585.

Grard, R., Hamelin, M., López-Moreno, J.J., Schwingenschuh, K., Jernej, I., Molina-Cuberos, G.J., Simões, F., Trautner, R., Falkner, P., Ferri, F., Fulchignoni, M., Rodrigo, R., Svedhem, H., Béghin, C., Berthelier, J.-J., Brown, V.J.G., Chabassière, M., Jeronimo, J.M., Lara, L.M., Tokano, T. 2006. Electric properties and related physical characteristics of the atmosphere and surface of Titan. Planet. Space Sci. 54, 1124-1136.

Grasset, O., Sotin, C. 1996. The cooling rate of a liquid shell in Titan's interior. Icarus 123, 101-112. 
Guglielmi, A.V., Pokhotelov, O. A. 1996. Geoelectromagnetic waves. Institute of Physics Publishing, London, UK.

Gurnett, D. A., Shaw, R. R., Anderson, R. R., Kurth, W. S. 1979. Whistlers observed by Voyager 1 - Detection of lightning on Jupiter. Geophys. Res. Lett. 6, 511-514.

Gurnett, D. A., Kurth, W. S., Cairns, I. H., Granroth, L. J. 1990. Whistlers in Neptune's magnetosphere - Evidence of atmospheric lightning. J. Geophys. Res. 95, 20967-20976.

Hamelin, M., Béghin, C., Grard, R., López-Moreno, J.J., Schwingenschuh, K., Simões, F., Trautner, R., Berthelier, J.J., Brown, V.J.G., Chabassière, M., Falkner, P., Ferri, F., Fulchignoni, M., Jernej, I., Jeronimo, J.M., Molina-Cuberos, G.J., Rodrigo, R., Tokano, T. 2007. Electron conductivity and density profiles derived from the mutual impedance probe measurements performed during the descent of Huygens through the atmosphere of Titan. Planet. Space Sci., doi:10.1016/j.pss.2007.04.008.

Justus, C. G., Duvall, A., Keller, V. W., Spilker, T. R., Lockwood, M. K. 2005. Connecting atmospheric science and atmospheric models for aerocapture at Titan and the outer planets. Planet. Space Sci. 53, 601-605.

Kliore, A., Cain, D. L., Fjeldbo, G., Seidel, B. L., Rasool, S. I. 1974. Preliminary Results on the Atmospheres of Io and Jupiter from the Pioneer 10 S-Band Occultation Experiment. Science 183, 323-324. 
Kliore, A. J., Hinson, D. P., Flasar, F. M., Nagy, A. F., Cravens, T. E. 1997. The ionosphere of Europa from Galileo radio occultations. Science 277, 355-358.

Krauss, C. E., Horányi, M., Robertson, S. 2003. Experimental evidence for electrostatic discharging of dust near the surface of Mars. New J. Phys. 5, 70.1-70.9.

Lanzerotti, L. J., Rinnert, K., Dehmel, G., Gliem, F. O., Krider, E. P., Uman, M. A., Bach, J. 1986. Radio Frequency Signals in Jupiter's Atmosphere. Science 272, 858-860.

Lewis, J.S. 1995. Physics and chemistry of the Solar System. Academic Press, San Diego, California.

Lide, D.R. 2006. CRC Handbook of Chemistry and Physics, the 87th Edition. Taylor and Francis, Boca Raton, Florida.

Lindal, G. F. 1992. The atmosphere of Neptune - an analysis of radio occultation data acquired with Voyager 2. Astron. J. 103, 967-982.

Lindal, G. F., Lyons, J. R., Sweetnam, D. N., Eshleman, V. R., Hinson, D. P. 1987. The atmosphere of Uranus - Results of radio occultation measurements with Voyager 2. J. Geophys. Res. 92, 14987-15001.

Liu, J. 2006. Interaction of magnetic field and flow in the outer shells of giant planets. PhD Thesis, Caltech, California. 
Lunine, J.I., Stevenson, D.J. 1987. Clathrate and ammonia hydrates at high pressureapplication to the origin of methane on Titan. Icarus 70, 61-77.

Majeed, T., Waite, J. H., Bougher, S. W., Yelle, R. V., Gladstone, G. R., McConnell, J. C., Bhardwaj, A. 2004. The ionospheres-thermospheres of the giant planets. Adv. Space Res. 33, $197-211$.

Molina-Cuberos, G. J., J. Porti, B. P. Besser, J. A. Morente, J. Margineda, H. I. M. Lichtenegger, A. Salinas, K. Schwingenschuh, and H. U. Eichelberger (2004), Schumann resonances and electromagnetic transparence in the atmosphere of Titan, Adv. Space Res., 33, 2309-2313.

Molina-Cuberos, G.J., Morente, J. A., Besser, B. P., Portí, J., Lichtenegger, H., Schwingenschuh, K., Salinas, A., Margineda, J. 2006. Schumann resonances as a tool to study the lower ionospheric structure of Mars. Radio Sci. 41, RS1003.

Morente, J. A., Molina-Cuberos, G. J., Portí, J. A., Schwingenschuh, K., Besser, B. P. 2003. A study of the propagation of electromagnetic waves in Titan's atmosphere with the TLM numerical method. Icarus 162, 374-384.

Nickolaenko, A.P. and Rabinovich, L.M. 1982. The possibility of existence of global electromagnetic resonances on solar-system planets (in Russian). Kosm. Issled. 20, 82-88.

Nickolaenko, A. P., Hayakawa, M. 2002. Resonances in the Earth-ionosphere cavity. Kluwer Academic Publishers, Dordrecht, The Netherlands. 
Nickolaenko, A. P., Besser, B. P., Schwingenschuh, K. 2003. Model computations of Schumann resonance on Titan. Planet. Space Sci. 51, 853-862.

Pätzold, M., Tellmann, S., Häusler, B., Hinson, D., Schaa, R., Tyler, G. L. 2005. A Sporadic Third Layer in the Ionosphere of Mars. Science 310, 837-839.

Pechony, O., Price, C. 2004. Schumann resonance parameters calculated with a partially uniform knee model on Earth, Venus, Mars, and Titan. Radio Sci. 39, RS5007.

Pettengill, G.H., Ford, P.G., Chapman, B.D. 1988. Venus - Surface electromagnetic properties. J. Geophys. Res. 93, 14881-14892.

Polk, C. 1969. Relation of ELF noise and Schumann resonances to thunderstorm activity. In: Coronoti, S.C. and Hughes, J. (Eds.) Planetary electrodynamics, 2, Gordon and Breach, New York, pp. 55-83.

Rakov, V. and Uman, M. 2003. Lightning. Cambridge Univ. Press, Cambridge, UK.

Russell, C.T. 1991. Venus lightning. Space Sci. Rev. 55, 317-356.

Russell, C.T. 2000. Some simple guidelines to the interpretation of the magnetic signatures seen at the galilean moons. Adv. Space Res. 26, 1653-1664. 
Schumann, W. O. 1952. On the free oscillations of a conducting sphere which is surrounded by an air layer and an ionosphere shell (in German). Z. Naturforsch. A, 7, 149-154.

Sentman, D.D. 1990. Electrical conductivity of Jupiter's shallow interior and the formation of a resonant of a resonant planetary-ionospheric cavity. Icarus 88, 73-86.

Sentman, D.D. 1995. Schumann resonances. In: Volland, H. (Ed.) Handbook of atmospheric electrodynamics, CRC Press, Boca Raton, Florida.

Shanov, S., Yanev, Y., Lastovickova, M. 2000. Temperature dependence of the electrical conductivity of granite and quartz-monzonite from south Bulgaria: geodynamic inferences. J. Balkan Geophys. Soc. 3, 13-19.

Simões, F., Grard, R., Hamelin, M., López-Moreno, J.J., Schwingenschuh, K., Béghin, C., Berthelier, J.-J., Besser, B., Brown, V.J.G., Chabassière, M., Falkner, P., Ferri, F., Fulchignoni, M., Hofe, R., Jernej, I., Jeronimo, J.M., Molina-Cuberos, G.J., Rodrigo, R., Svedhem, H., Tokano, T., Trautner, R., 2007. A new numerical model for the simulation of ELF wave propagation and the computation of eigenmodes in the atmosphere of Titan: did Huygens observe any Schumann resonance? Planet. Space Sci., doi:10.1016/j.pss.2007.04.016.

Sohl, F., Sears, W.D., Lorenz, R.D. 1995. Tidal dissipation on Titan. Icarus 115, 278-294. 
Squyres, S.W., Clifford, S.M., Kuzmin, R.O., Zimbelman, J.R., Costard, F.M. 1992. Ice in the Martian regolith. In: Kieffer, H.H., Jakosky, B.M., Snyder, C.W., Matthews, M.S. (Eds.) Mars, Univ. of Arizona Press, Tucson, Arizona, pp. 523-554.

Strangeway, R.J. 2004. Plasma waves and electromagnetic radiation at Venus and Mars. Adv. Space Res. 33, 1956-1967.

Sukhorukov, A.I. 1991. On the Schumann resonances on Mars. Planet. Space Sci. 39, 16731676.

Tobie, G., Grasset, O., Lunine, J.I., Mocquet, A., Sotin, C. 2005. Titan's internal structure inferred from a coupled thermal-orbital model. Icarus 175, 496-502.

Tobie, G., Lunine, J.I., Sotin, C. 2006. Episodic outgassing as the origin of atmospheric methane on Titan. Nature 440, 61-64.

Wahlund, J.-E., Boström, R., Gustafsson, G., Gurnett, D. A., Kurth, W. S., Pedersen, A., Averkamp, T. F., Hospodarsky, G. B., Persoon, A. M., Canu, P., Neubauer, F. M., Dougherty, M. K., Eriksson, A. I., Morooka, M. W., Gill, R., André, M., Eliasson, L., Müller-Wodarg, I. 2005. Cassini Measurements of Cold Plasma in the Ionosphere of Titan. Science 308, 986989.

Williams, E. 1992. The Schumann resonance: A global tropical thermometer. Science 256, 1184-1187. 
Woan, G. 1999. The Cambridge handbook of physics formulas. Cambridge University Press, Cambridge, UK.

Yang, H., Pasko, V.P., Yair, Y. 2006. Three-dimensional finite difference time domain modeling of the Schumann resonance parameters on Titan, Venus, and Mars. Radio Sci. 41, RS2S03, doi:10.1029/2005RS003431.

Zarka, P., Pedersen, B. M. 1986. Radio detection of Uranian lightning by Voyager 2. Nature $323,605-608$.

Zimmerman, W.B.J. 2006. Multiphysics modelling with finite element methods. World Scientific, Oxon, UK. 


\section{Tables}

Table 1: Configuration and lowest resonance frequency of selected geophysical cavities.

\begin{tabular}{|l|c|c|c|c|c|}
\hline \multicolumn{1}{|c|}{ Body } & $\boldsymbol{R}_{\boldsymbol{p}} \mathbf{\mathbf { k m } ]}$ & $\begin{array}{c}\boldsymbol{h} \\
\text { for } \mathbf{\sigma} \mathbf{\mathbf { 1 0 } ^ { - 3 }} \mathbf{S m}^{-\mathbf{1}} \mathbf{\mathbf { k m } ]}\end{array}$ & $\boldsymbol{d} \mathbf{\mathbf { k m } ]}$ & $\boldsymbol{h} / \boldsymbol{R}_{\boldsymbol{p}}$ & $\begin{array}{c}\text { Frequency [Hz] } \\
\text { (Eq. 01) }\end{array}$ \\
\hline Venus & 6052 & 130 & 40 & 0.022 & 11.2 \\
\hline Earth & 6378 & 100 & 0 & 0.016 & 10.6 \\
\hline Mars & 3397 & 100 & 10 & 0.030 & 19.9 \\
\hline Jupiter & 71493 & 900 & 2000 & 0.013 & 0.9 \\
\hline Saturn & 60268 & 600 & 5500 & 0.010 & 1.1 \\
\hline Titan & 2575 & 750 & 100 & 0.291 & 26.2 \\
\hline Uranus & 25559 & $600(?)$ & 5000 & 0.024 & 2.6 \\
\hline Neptune & 24764 & $400(?)$ & 4000 & 0.016 & 2.7 \\
\hline
\end{tabular}

Table 2: Major energy sources in various cavities.

\begin{tabular}{|l|l|l|}
\hline Body & Electromagnetic source & Reference \\
\hline Venus & Possibly lightning & Russel (1991); Strangeway (2004) \\
\hline Earth & Lightning & e.g. Nickolaenko and Hayakawa (2002) \\
\hline Mars & Possibly dust devils / dust storms & Farrell and Desch (2001); Aplin (2006) \\
\hline Jupiter & Lightning & Gurnett et al. (1979); Lanzerotti et al. (1996) \\
\hline Saturn & Lightning & Fischer et al. (2006) \\
\hline Titan & Possibly lightning / haze & Fischer et al. (2004); Béghin et al. (2007) \\
\hline Uranus & Likely lightning & Zarka and Pedersen (1986) \\
\hline Neptune & Likely lightning & Gurnett et al. (1990) \\
\hline
\end{tabular}

Table 3: The complex frequency of the three lowest Schumann resonances calculated with the finite element model. For the sake of comparison, other results are also given, but all have been obtained with different approaches.

\begin{tabular}{|c|c|c|c|c|c|c|c|c|c|}
\hline \multirow{2}{*}{$\begin{array}{c}\text { Planetary } \\
\text { body }\end{array}$} & \multicolumn{4}{|c|}{ Parameters } & \multicolumn{3}{|c|}{ Computed Resonance Frequency } & \multicolumn{2}{|r|}{ Former results } \\
\hline & Atmosphere & $\varepsilon_{\text {int }}-[1]$ & $\sigma_{\text {int }}-\left[\mathrm{Sm}^{-1}\right]$ & $\mathrm{d}-[\mathrm{km}]$ & $n=1$ & $n=2$ & $n=3$ & $n=1$ & Reference \\
\hline Venus & Fig. 2 & $\begin{array}{c}- \\
{[5,10]} \\
{[5,10]}\end{array}$ & $\begin{array}{l}\text { Fig. } 2-\mathrm{H} \\
\text { Fig. } 2-\mathrm{L}\end{array}$ & $\begin{array}{c}0 \\
150 \\
150\end{array}$ & $\begin{array}{l}9.01+0.56 i \\
8.80+0.91 i \\
7.95+0.74 i\end{array}$ & $\begin{array}{l}15.81+0.97 i \\
15.77+1.38 i \\
14.17+1.20 i\end{array}$ & $\begin{array}{l}22.74+1.42 i \\
22.67+1.76 i \\
20.37+1.60 i\end{array}$ & $\begin{array}{l}11.2 \\
9 \\
10\end{array}$ & $\begin{array}{l}\text { Guglielmi and Pokhotelov (1996) } \\
\text { Nickolaenko and Hayakawa (2002) } \\
\text { Pechony and Price (2004) }\end{array}$ \\
\hline Earth & \multicolumn{4}{|c|}{ measured values } & $7.85+0.79 i$ & $13.95+1.33 i$ & $20.05+1.79 i$ & & Nickolaenko and Hayakawa (2002) \\
\hline Mars & Fig. 3 & $\begin{array}{c}{[5,10]} \\
5 \\
10 \\
{[5,10]} \\
5 \\
10 \\
\end{array}$ & $\begin{array}{c}- \\
10^{-7} \\
10^{-10} \\
10^{-10} \\
10^{-7} \\
10^{-10} \\
10^{-10}\end{array}$ & $\begin{array}{c}0 \\
5 \\
5 \\
5 \\
10 \\
10 \\
10 \\
\end{array}$ & $\begin{array}{l}8.31+2.19 i \\
8.28+2.10 i \\
8.55+2.07 i \\
8.41+2.08 i \\
7.93+2.06 i \\
8.47+2.03 i \\
8.20+2.03 i\end{array}$ & $\begin{array}{l}15.64+4.27 i \\
15.49+3.66 i \\
15.93+3.62 i \\
15.72+3.63 i \\
14.93+3.94 i \\
15.85+3.89 i \\
15.40+3.89 i\end{array}$ & $\begin{array}{l}23.51+6.59 i \\
22.82+5.53 i \\
23.44+5.49 i \\
23.13+5.49 i \\
22.41+6.04 i \\
23.68+5.97 i \\
23.05+5.96 i\end{array}$ & $\begin{array}{l}13 \\
8.6 \\
11-12\end{array}$ & $\begin{array}{l}\text { Sukhorukov (1991) } \\
\text { Pechony and Price (2004) } \\
\text { Molina-Cuberos et al. (2006) }\end{array}$ \\
\hline Jupiter & Fig. 5 & \multicolumn{3}{|c|}{ Fig. 4 and 6} & $0.68+0.04 i$ & $1.21+0.07 i$ & $1.74+0.10 i$ & $\begin{array}{l}0.76 \\
0.95 \\
1\end{array}$ & $\begin{array}{l}\text { Sentman (1990) } \\
\text { Guglielmi and Pokhotelov (1996) } \\
\text { Nickolaenko and Hayakawa (2002) }\end{array}$ \\
\hline Io & negligible & \multicolumn{3}{|c|}{-} & \multicolumn{3}{|c|}{ evanescent wave } & - & Nickolaenko and Rabinovich (1982) \\
\hline Europa & negligible & \multicolumn{3}{|c|}{-} & \multicolumn{3}{|c|}{ evanescent wave } & - & - \\
\hline Saturn & Fig. 5 & \multicolumn{3}{|c|}{ Fig. 4 and 6} & $0.93+0.06 i$ & $1.63+0.12 i$ & $2.34+0.18 i$ & - & - \\
\hline Titan & $\begin{array}{l}\text { Fig. } 7-\text { high } \\
\text { Fig. } 7-\text { low }\end{array}$ & $\begin{array}{l}3 \\
3\end{array}$ & $\begin{array}{l}10^{-9} \\
10^{-9}\end{array}$ & $\begin{array}{l}100 \\
100\end{array}$ & $\begin{array}{l}13.43+6.25 i \\
19.15+2.27 i\end{array}$ & $\begin{array}{l}28.13+10.57 i \\
34.32+3.71 i\end{array}$ & $\begin{array}{l}43.93+13.64 i \\
49.48+5.22 i\end{array}$ & $\begin{array}{l}11-15 \\
17-20 \\
8-10\end{array}$ & $\begin{array}{l}\text { Morente et al. (2003) } \\
\text { Nickolaenko et al. (2003) } \\
\text { Yang et al. (2006) }\end{array}$ \\
\hline Uranus & \multicolumn{4}{|c|}{$\begin{array}{ll}\text { Fig. 8-10 } & \text { ingress }- \text { low water content } \\
\text { Fig. 8-10 } & \text { ingress }- \text { high water content } \\
\text { Fig. 8-10 } & \text { egress }- \text { low water content } \\
\text { Fig. 8-10 } & \text { egress }- \text { high water content }\end{array}$} & $\begin{array}{l}2.44+0.06 i \\
1.02+0.25 i \\
2.47+0.06 i \\
1.12+0.33 i\end{array}$ & $\begin{array}{l}4.24+0.11 i \\
1.99+0.49 i \\
4.27+0.11 i \\
2.17+0.58 i\end{array}$ & $\begin{array}{l}6.00+0.15 i \\
3.03+0.67 i \\
6.04+0.16 i \\
3.26+0.82 i\end{array}$ & - & - \\
\hline Neptune & \multicolumn{2}{|c|}{$\begin{array}{l}\text { Fig. } 8-10 \\
\text { Fig. } 8-10\end{array}$} & \multicolumn{2}{|c|}{$\begin{array}{l}\text { ligh water content } \\
\text { low water content }\end{array}$} & $\begin{array}{l}1.10+0.54 i \\
2.33+0.12 i\end{array}$ & $\begin{array}{l}2.03+0.96 i \\
4.12+0.22 i\end{array}$ & $\begin{array}{l}2.96+1.69 i \\
5.90+0.31 i\end{array}$ & - & - \\
\hline
\end{tabular}




\section{Figure Captions:}

Fig. 1: Sketch of the model used for calculating the Schumann resonance. $R_{P}$ : Planet radius; $R_{\text {int }}$ : lower boundary radius; $R_{\text {ext }}$ : ionosphere radius; $h$ : altitude of the ionosphere; $d$ : depth of the lower boundary; $\sigma_{\text {surf }}-$ surface conductivity; $\varepsilon_{i n t}, \varepsilon_{\text {atm }}, \sigma_{\text {int }}, \sigma_{a t m}$ - permittivities and conductivities of the interior and atmosphere, respectively.

Fig. 2: Dielectric parameters of the Venusian cavity. Left: Conductivities as functions of depth for high (solid) and low (dashed) surface conductivities; Right: conductivity (solid) and permittivity (dashed) of the atmosphere.

Fig. 3: Conductivity profile of the Martian atmosphere.

Fig. 4: Permittivity profiles of Jupiter (solid) and Saturn (dashed) interiors.

Fig. 5: Conductivity profiles of Jupiter (solid) and Saturn (dashed) atmospheres.

Fig. 6: Conductivity profiles of Jupiter (solid) and Saturn (dashed) interiors.

Fig. 7: Atmospheric conductivity profiles based on the Huygens preliminary results at altitudes less than $150 \mathrm{~km}$, for high $(\mathrm{H})$ and low $(\mathrm{L})$ aerosol concentrations. The profiles match the electron conductivity derived from the measurements of Cassini and Voyager at $\sim 750 \mathrm{~km}$.

Fig. 8: Permittivity profiles of Uranus (solid) and Neptune (dashed) interiors.

Fig. 9: Conductivity profiles of Uranus and Neptune interiors for gravimetric water contents of 0 (solid) and $15 \%$ (dashed).

Fig. 10: Atmospheric conductivity profiles of Uranus (solid - ingress; dashed - egress) and Neptune (dotted). 
Figures

Figure 1

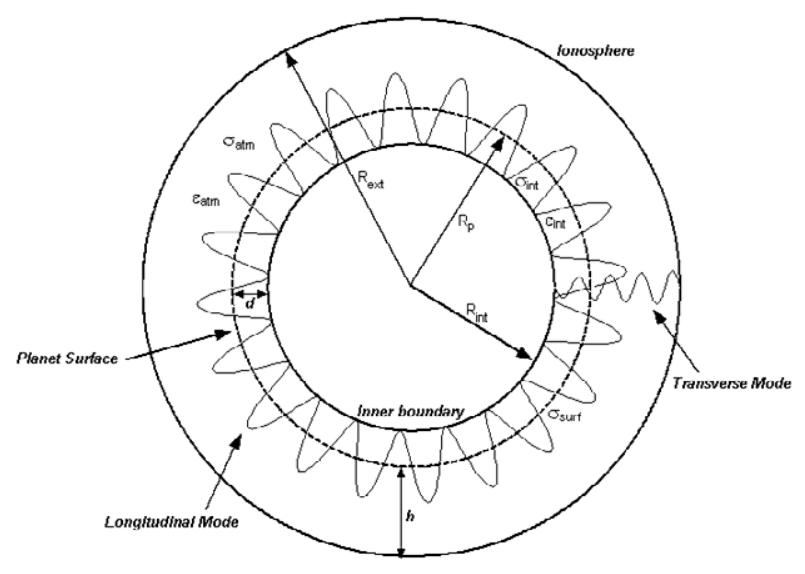

Figure $2(a, b)$

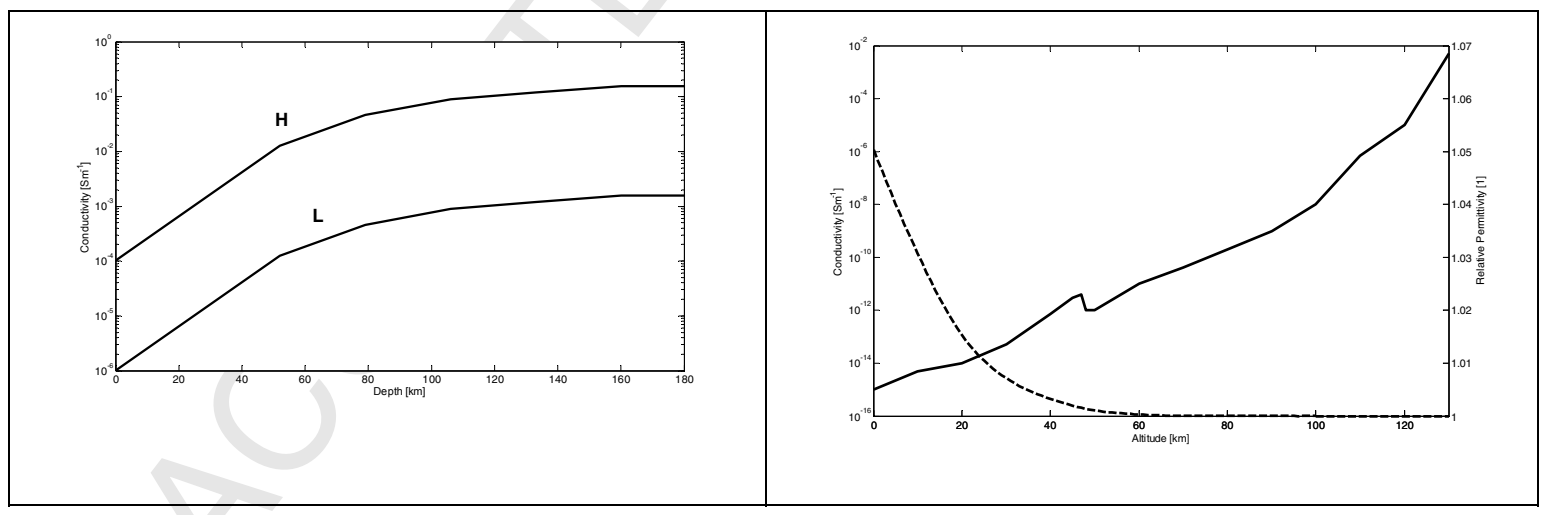


Figure 3

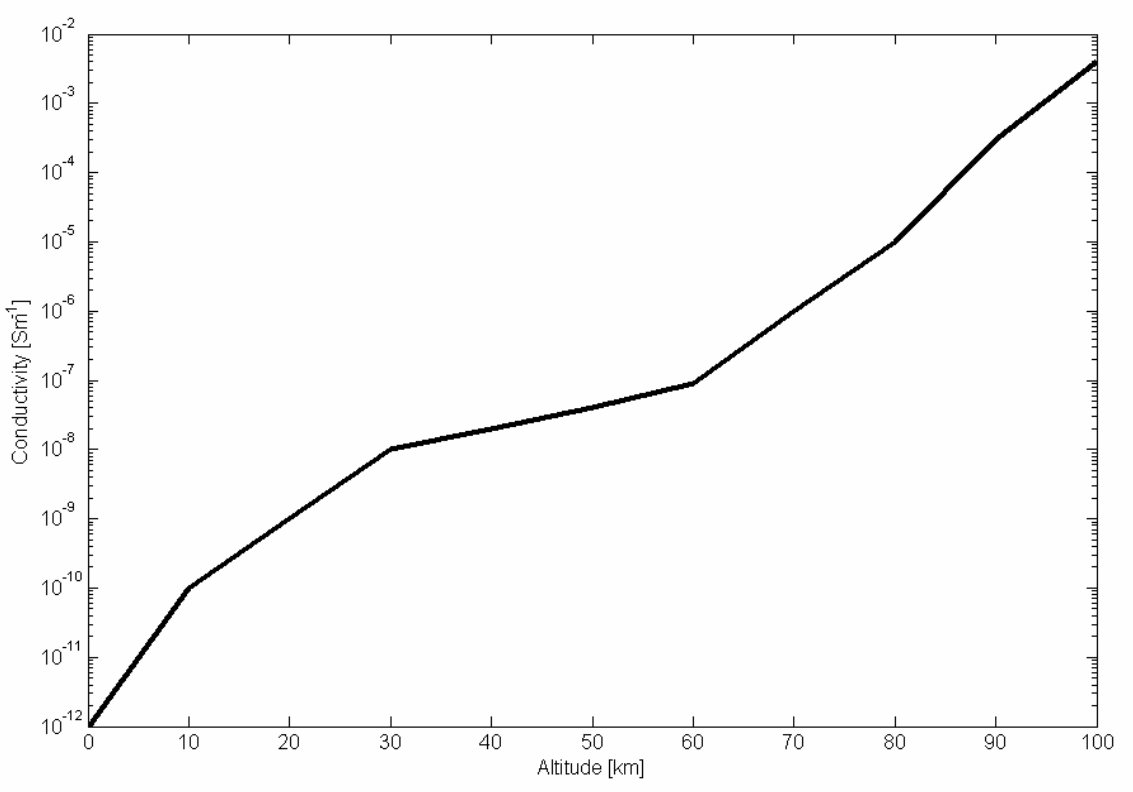

Figure 4

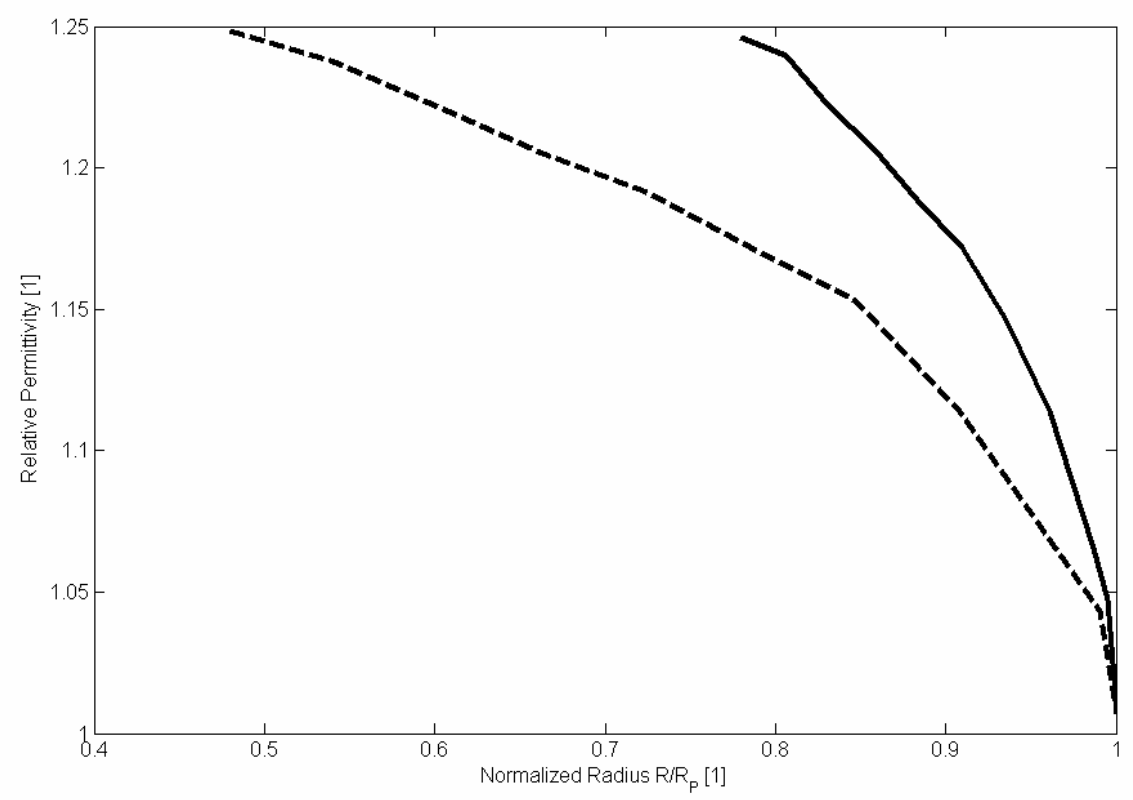


Figure 5

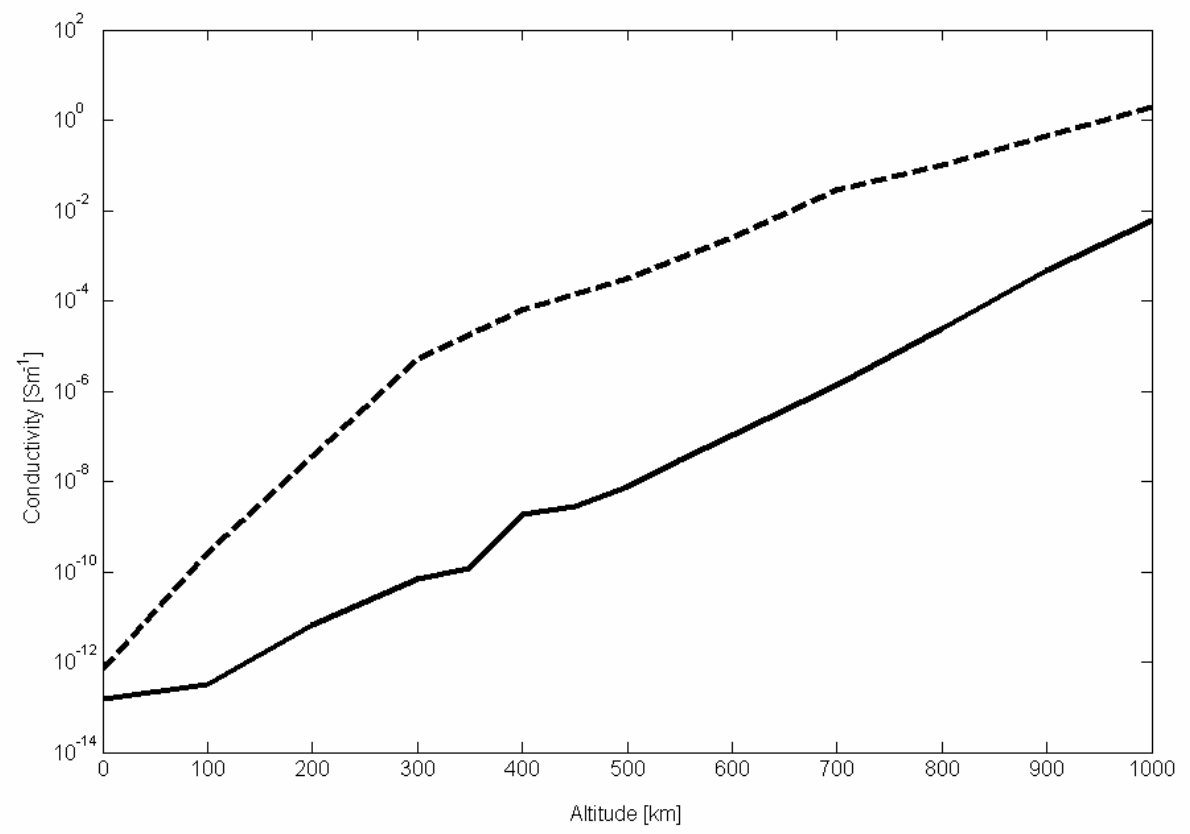

Figure 6

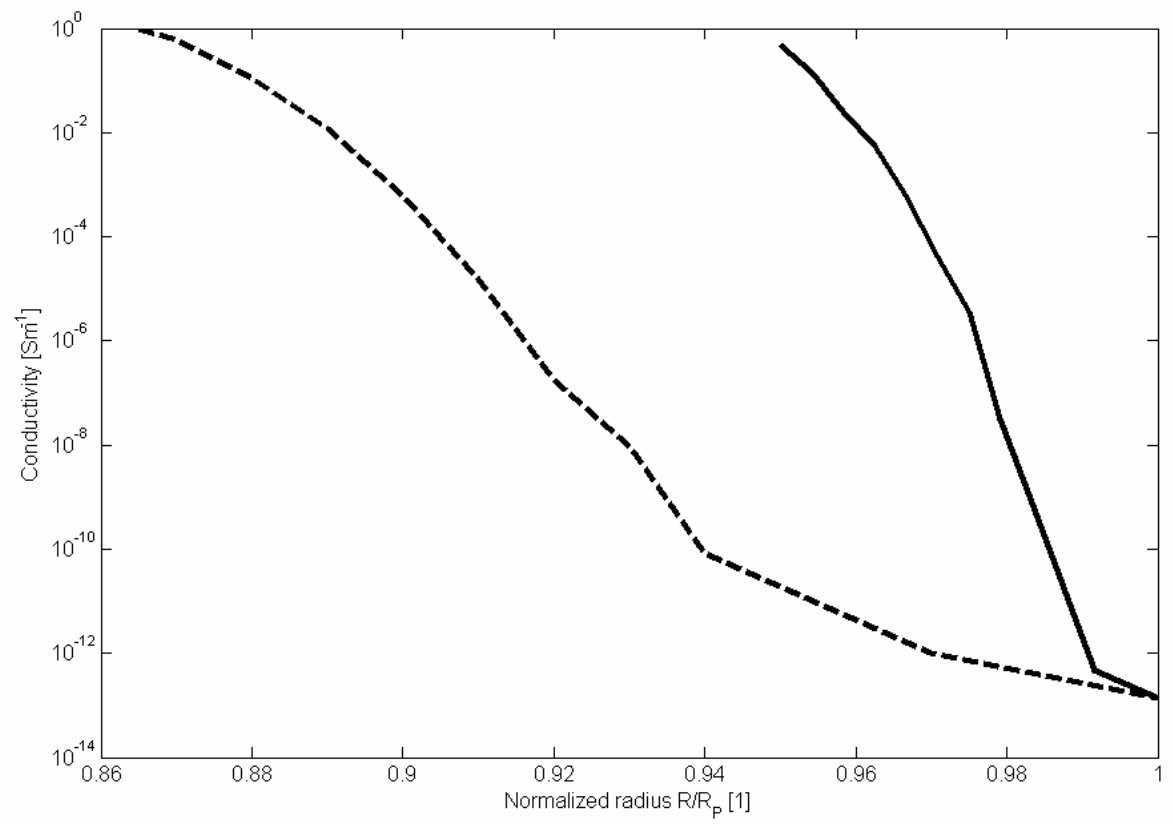


Figure 7

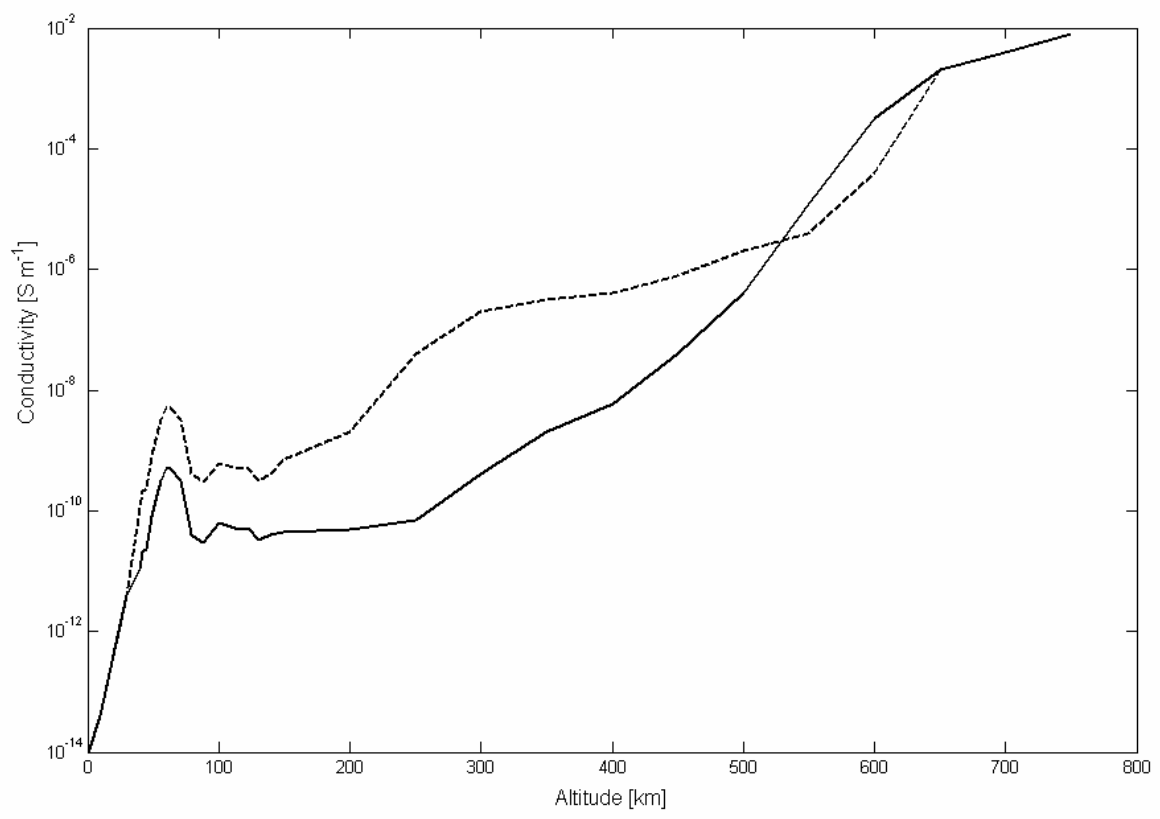

Figure 8

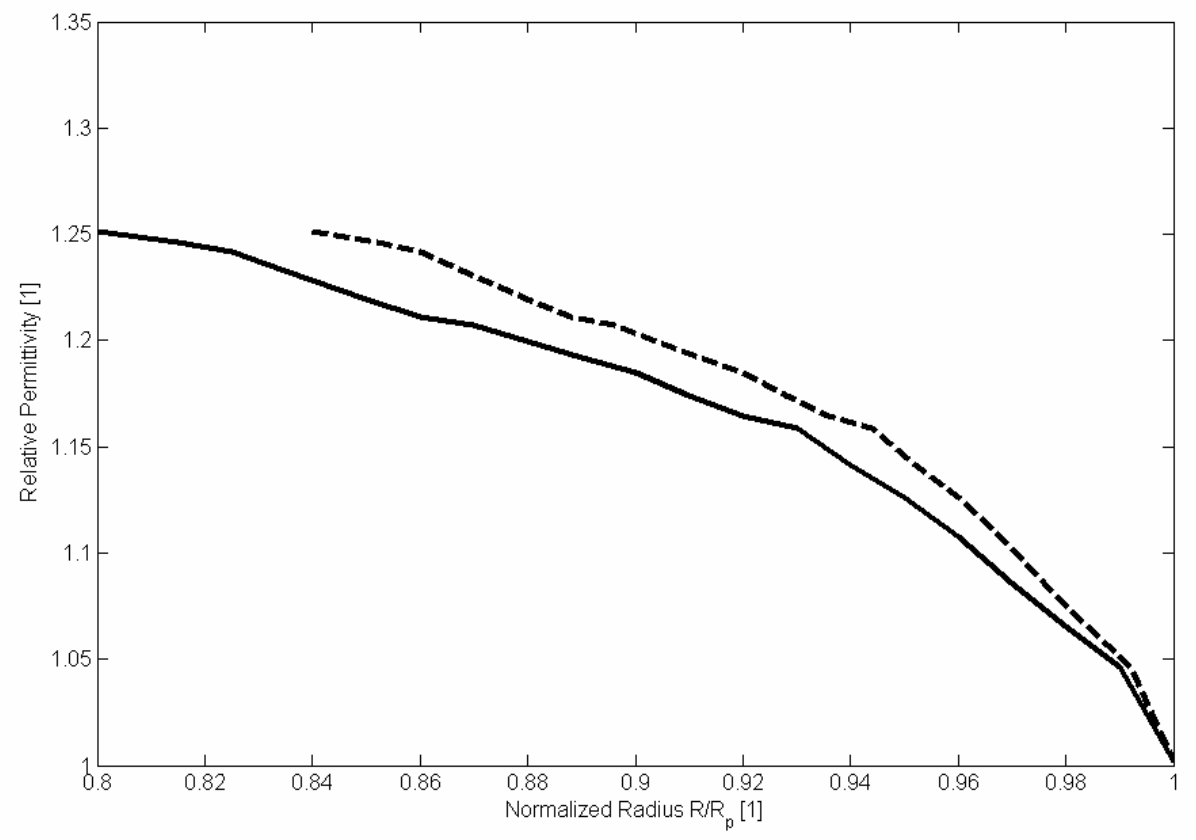


Figure 9

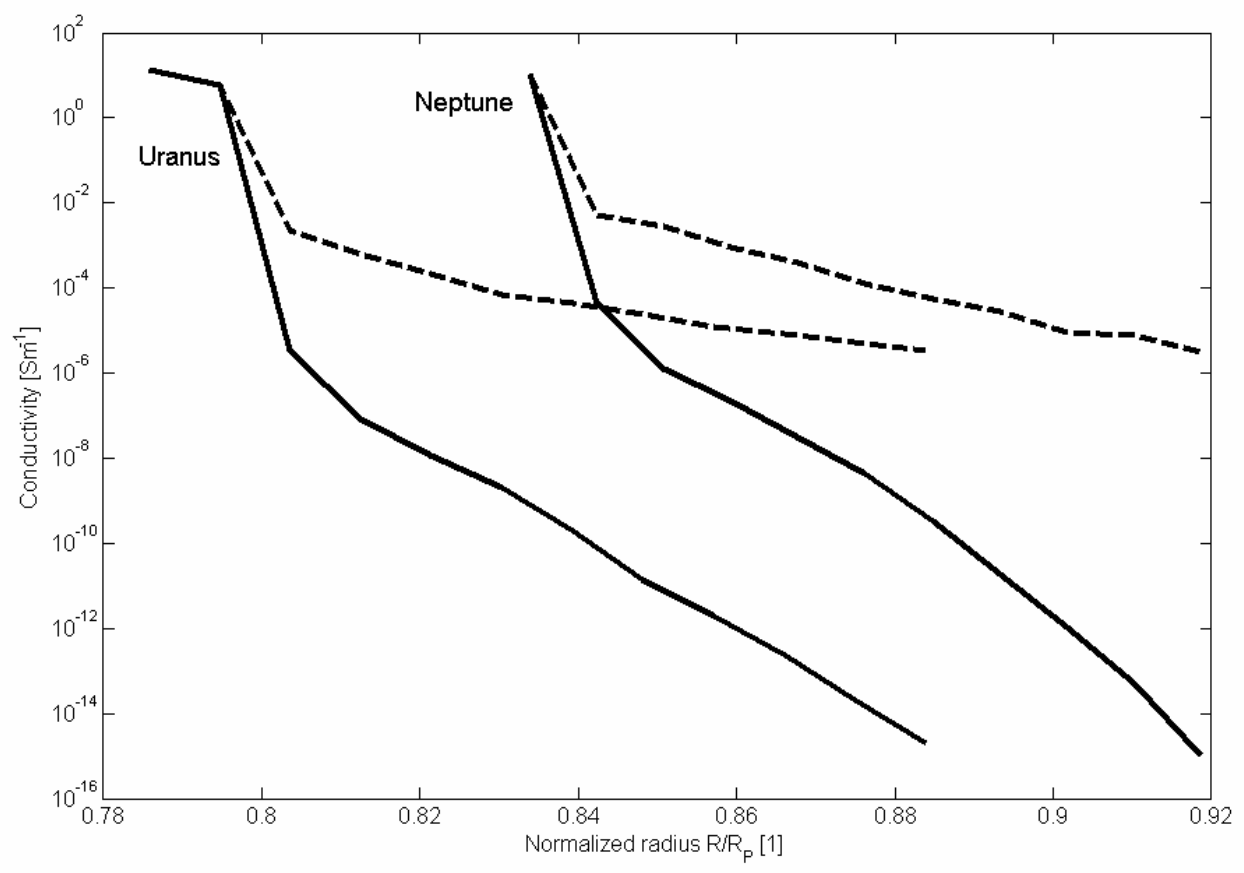

Figure 10

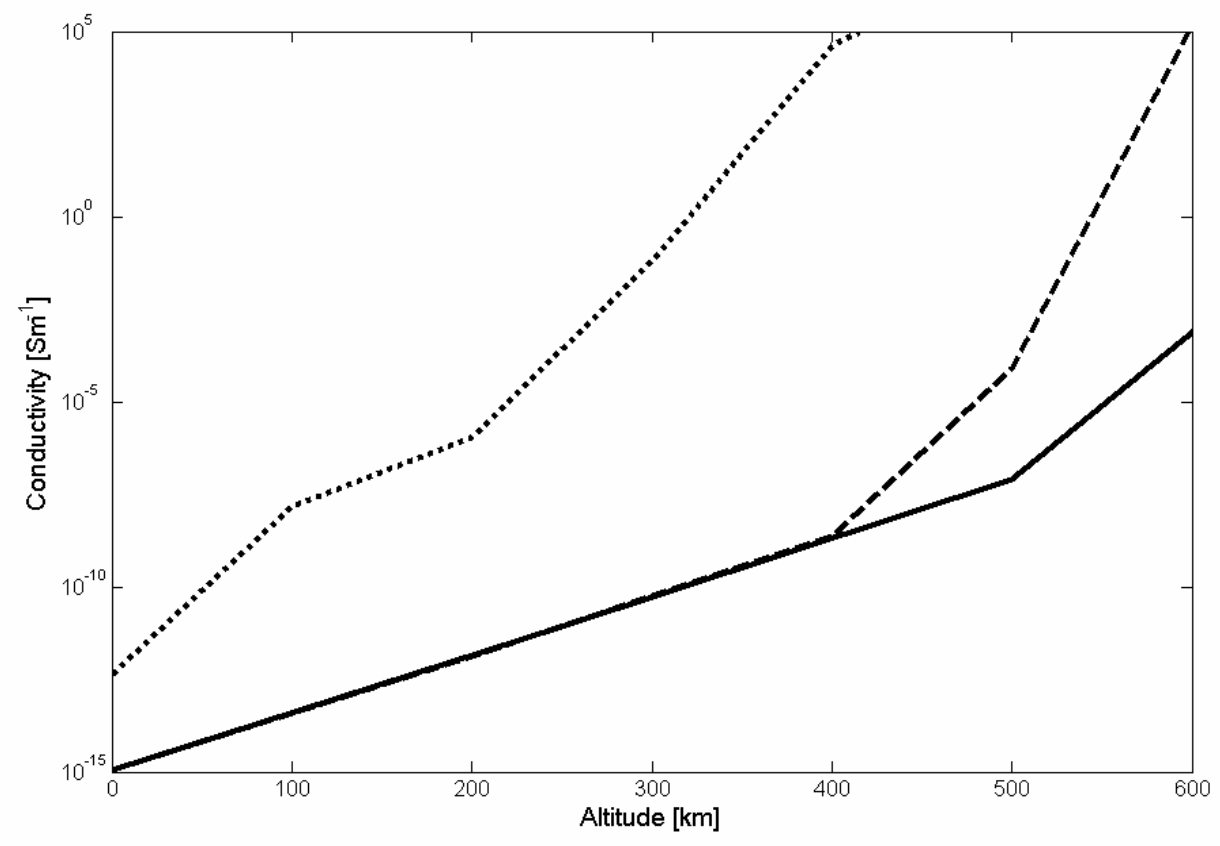

